How to cite: Kocsis, I., Haidu, I., Maier, N. (2020) Application of a Hydrological MIKE HYDRO River - UHM Model for Valea Rea River (Romania). Case Study, Flash Flood Event Occurred on August 1", 2019. 2020 "'Air and Water - Components of the Environment" Conference Proceedings, Cluj-Napoca, Romania, p. 257-272, DOI: 10.24193/AWC2020_24.

\title{
APPLICATION OF A HYDROLOGICAL MIKE HYDRO RIVER - UHM MODEL FOR VALEA REA RIVER (ROMANIA). CASE STUDY, FLASH FLOOD EVENT OCCURRED ON AUGUST $1^{\text {st }}, 2019$
}

\author{
István KOCSIS ${ }^{1}$, Ionel HAIDU ${ }^{2}$, Narcis MAIER ${ }^{3}$
}

DOI: 10.24193/AWC2020_24

\begin{abstract}
On August 1, 2019, the atmospheric instability was very pronounced in the hydrographic basin related to the Călinești-Oaș Reservoir, the main phenomenon being the local rainstorms, of very high intensity. The successive radar images, observed in real time, predicted the outbreak of a hydrometeorological event with a strong impact in the catchment basin of the Huta Certeze hydrometric station, on Valea Rea river (the upper hydrographic basin of the Tur river, Oașului Mountains, Satu-Mare district). In a very short time of only 4 hours, a total of $132.5 \mathrm{~mm}$ precipitation was measured, which generated a flash flood with a single peak, exceeding the flooding stages, with a maximum discharge of $46.6 \mathrm{~m}^{3} / \mathrm{s}$. Being an extreme hydrometeorological phenomenon, the question arises to verify whether it is possible to modeling a flash flood of an almost unprecedented magnitude. For modelling purpose MIKE HYDRO River - UHM (Unit Hydrograph) has been selected, being the most suitable for the unit hydrograph method, when the inputs are generated by a single storm event. A GIS based application; ArcMap was used to delimit the affected catchment area. The simulated discharge hydrographs were compared with the observed one at the Huta Certeze hydrometric station, which represent the closing point of the studied basin. The obtained results confirm the modeling's veracity. Therefor MIKE HYDRO River can be used for forecasting water flows to rivers or lakes, for estimating water resources, as well as for river basin management.
\end{abstract}

Keywords: Valea Rea, MIKE HYDRO River, UHM, hydrological modelling, flash flood

\section{INTRODUCTION}

The floods represent peak times in the evolution of the water flow of a river. $\mathrm{M}$. Pardé (1969) considers them to be "the most dramatic episodes of hydrology". They are characterized by very rapid (hourly scale), sometimes extraordinary increases of water level and implicitly of the discharge, until a maximum is reached, followed by the also rapid decrease of the waters (but in a slower rate than the increase), which

\footnotetext{
${ }^{1}$ Babeș-Bolyai University, Faculty of Geography, 5-7, Clinicilor Street, Cluj-Napoca, 400006, Cluj Country, Romania, kfistvan@yahoo.com

${ }^{2}$ University of Lorraine, Laboratory LOTTER - EA 7304, 57045 Metz, ionel.haidu@univ-lorraine.fr

${ }^{3}$ National Meteorological Administration, Regional Meteorological Center "Transylvania North", 400213 Cluj-Napoca, Romania, mcis73@yahoo.com
} 
return to normal flow parameters (Pișota and Zaharia, 2002). Flash floods are among the most difficult natural hazards to predict in terms of time and place of occurrence. The areas and the hydro meteorological phenomena that lead to flash flood occurrence are challenging to identify (Ivănescu and Drobot, 2016). In small river basins with a concentration time of less than 6 hours, torrential rains can lead to flash floods. These floods can also occur under generalized rains, which locally in short periods (2-3 hours or less) have high intensities. Due to the speed with which they take place, flash floods mainly cause material damage but also loss of human life.

\section{MATERIAL AND METHODS}

\subsection{Description of the study area}

The Valea Rea river is located in the upper hydrographic basin of the Tur river, representing a right tributary of it, situated in the northwest of Romania and east part of Satu-Mare district, upstream of the Călinești-Oaș Reservoir (Fig.1).

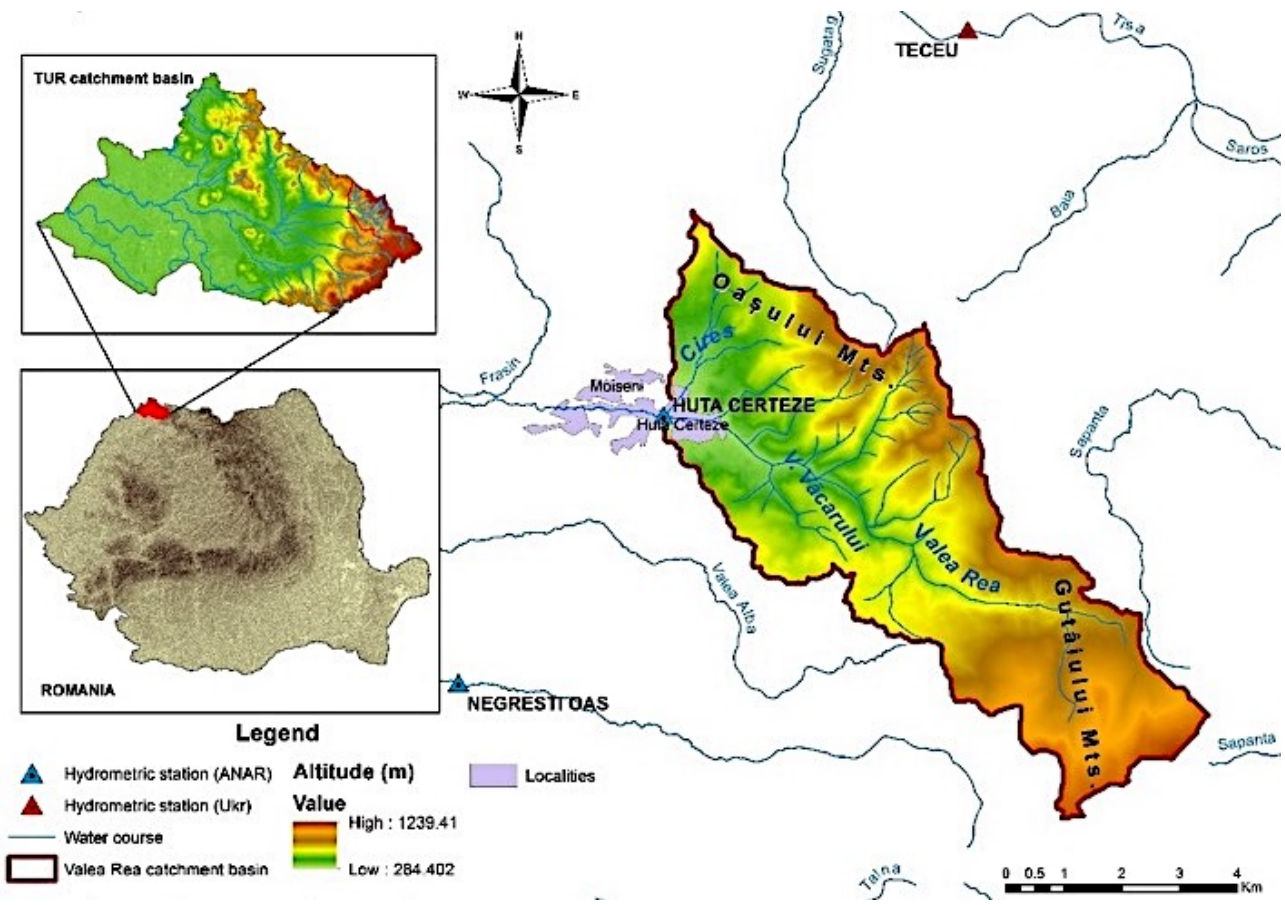

Fig. 1. Location of the study area

The upper section of the Valea Rea river, upstream of the Huta Certeze hydrometric station (h.s.), of a distinctly torrential character, with a length of the river course of 14 $\mathrm{km}$ and the surface of catchment basin of $61.3 \mathrm{~km}^{2}$ was chosen for the study of flash floods. The main tributary, with the biggest contribution of water is Valea Cireș river (rg.), the confluence with Valea Rea being immediately upstream of the h.s. 
The monitoring of hydrometeorological data is done through Huta Certeze h.s., representing the closing section of the studied hydrographic basin. Huta Certeze h.s., the first one on the Valea Rea was established in 1966, and is administrated by the Romanian National Water Administration, through Satu-Mare Water Management System. Since 2006 the h.s. was automated by sensors for monitoring hydrometeorological parameters, thus doubling the daily transmission of level and precipitation data with automatic, remote transmission data, provided at hourly intervals.

The calculated mean multi-annual water discharge is $1.83 \mathrm{~m}^{3} / \mathrm{s}$. The maximum historical discharge was $89.6 \mathrm{~m}^{3} / \mathrm{s}$, recorded between 12.05.-17.05.1970. The mean annual flow of various flood return probability is shown in table 1 (Haidu, 1993).

Table 1. The mean annual flow of various flood return probability, Valea Rea river, Huta Certeze h.s.

\begin{tabular}{|c|c|c|c|c|c|c|c|c|c|c|}
\hline \multirow{2}{*}{ River - H.S. } & \multicolumn{5}{|c|}{$\mathrm{Q} \%, \mathrm{~m}^{3} / \mathrm{s}$} & \multicolumn{5}{c|}{$\mathrm{q} \%, 1 / \mathrm{s} / \mathrm{km}^{2}$} \\
\cline { 2 - 10 } & $5 \%$ & $10 \%$ & $50 \%$ & $90 \%$ & $95 \%$ & $5 \%$ & $10 \%$ & $50 \%$ & $90 \%$ & $95 \%$ \\
\hline $\begin{array}{c}\text { Valea Rea - } \\
\text { Huta Certeze }\end{array}$ & 2,8 & 2,6 & 1,7 & 1,2 & 1,1 & 46,8 & 44,5 & 29,5 & 20,0 & 19,2 \\
\hline
\end{tabular}
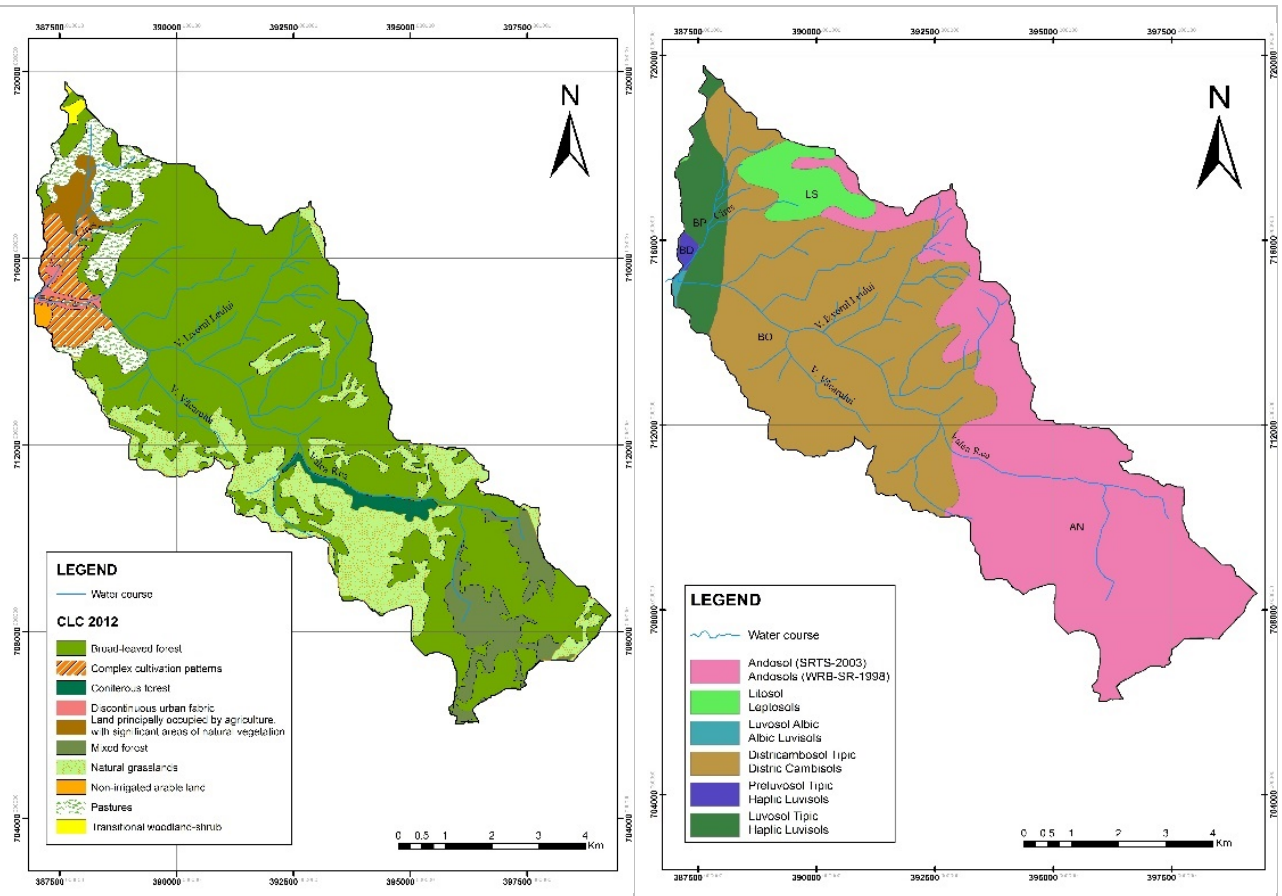

Fig. 2. Land use according to CLC 2012

Fig. 3. Pedogeographic characteristics

The inhabited areas exposed to the floods are represented by the villages Huta Certeze and Moișeni, members of the commune Certeze. According to the National Institute of Statistics, at the 2011 census the permanent population was 1704 inhabitants in Huta Certeze and 1391 in Moișeni. 
The layout of the hydrographic basin on diversified relief steps, with the altitude increasing from $284 \mathrm{~m}$ in the Oașului Depression to $1239 \mathrm{~m}$ in the high mountainous area of the Oașului and Gutâiului Mt., with the average altitude (Hm) of $719 \mathrm{mdMN}$ (m above the Black Sea), results in a varied and well preserved natural vegetation. The spatial distribution of the land-use, obtained from Corine Land Cover (CLC) 2012 raster datasets (available from the European Environment Agency), shows that the studied catchment basin has a high degree of afforestation (70.46\%), being mainly occupied by broad-leaved forests $63.12 \%$. Coniferous forests represent $1.41 \%$ and mixed forests $5.93 \%$. Relatively large areas are occupied by natural pastures, in percent of $17.75 \%$. Around the locality of Huta Certeze the areas of complex cultivation patterns (3.66\%), land principally occupied by agriculture, with significant areas of natural vegetation $(1.68 \%)$, pastures $(5.31 \%)$ are predominant. The spatial distribution of land use is shown in Fig. 2.

Within the studied catchment basin, the most widespread soils are represented by District Cambisols, covering an area of 2767.08 ha (45.1\%), in the central part of the basin, respectively by Andosols, covering 2707.3 ha (44.1\%) in the upper part of the basin. In the lower part of the basin 354.47 ha (5.77\%) are occupied by Haplic Luvisols, 276.28 ha (4.50\%) Leptosols in the north-west, and the rest of 33.73 ha $(0.55 \%)$ are Haplic Luvisols and Albic Luvisols in the western extremity of the basin (Fig. 3).

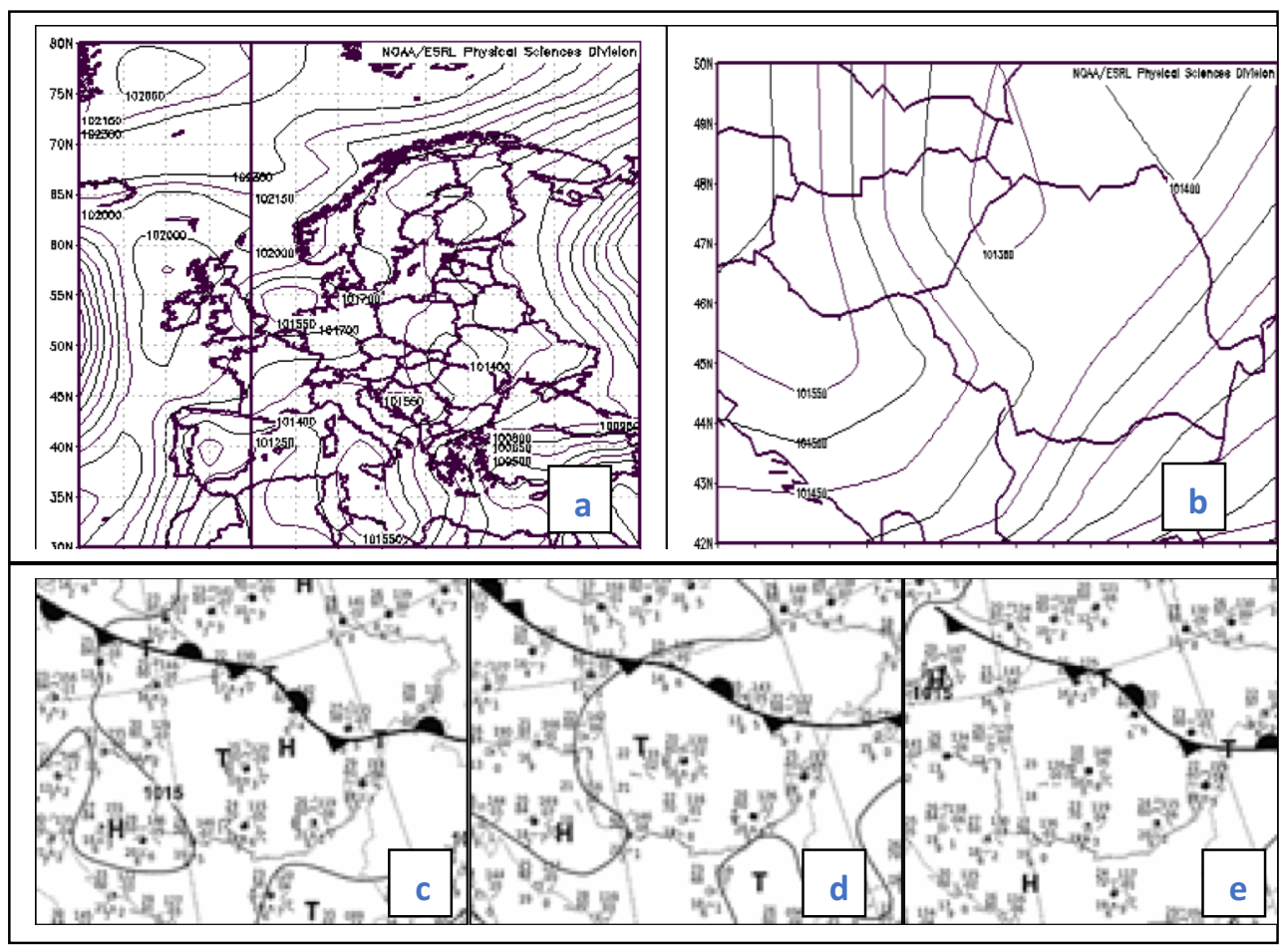

Fig. 4. Synoptic situation on 01.08.2019 at 12 UTC above Europe (a) and Romania (b) (https://www.esrl.noaa.gov/); Fronts situation (cold and warm) at 06 (c), 12 (d) and 18 UTC (e), (http://www1.wetter3.de). 
Depending on the texture of each soil type, the corresponding hydrological soil group can be assigned to them. Groups B and C completely occupy the study area, the soils being characterized by a medium and slightly above medium potential of runoff, and a low to medium infiltration rate (Chendeș 2011). The direct influence of LULC and soils on runoff was analyzed in a recent study by Strapazan et al. (2019).

\subsection{Data Sets}

In general, flash floods are the direct consequence of the climatic conditions. Detailed analysis of the climatic conditions, of the synoptic situation that generated the rapid increase of the flows is essential in order to interpret and perceive the hydrological event correctly.

On 01.08.2019 Southern and Eastern Europe was under the influence of a vast depression system in evolution. Above Romania, but especially over the northwest area was a small stationary cyclone, visible only at the bottom part of the atmosphere (Fig. 4a and b). In Fig. 4c, d and e are presented the cold and warm fronts, related to the cyclone at 6,12 and 18 UTC, observing their stationarity. This small orographic cyclone located in the northwest of Romania was supported by a powerful divergence observed at the level of $300 \mathrm{mb}(9122 \mathrm{~m})$, as shown is Fig. 5.

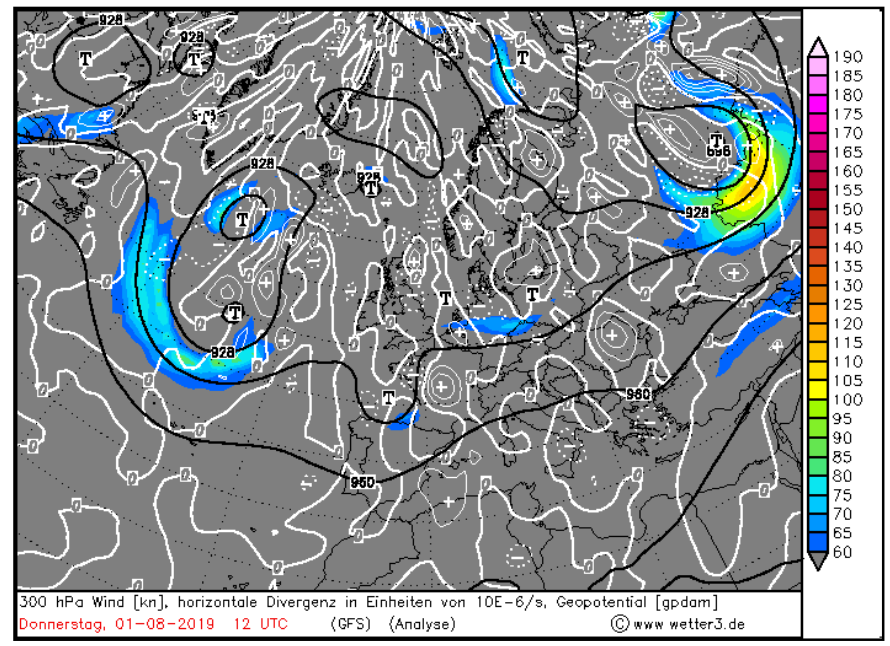

Fig. 5. Horizontal divergence at $300 \mathrm{mb}$ on 01.08.2019 at 12 UTC, (http://www1.wetter3.de).

On 01.08.2019 the Lifted Index (Fig. 6) had a value $<-2$, which indicates an increased instability in the area. All these factors have made possible that the cloud system developed during the afternoon and evening to be generally stationary.

Together with the orographic characteristics of the area, the orientation of the basin on the east-vest direction created favorable conditions to accumulating huge quantities of precipitations in a very short time, especially on the slopes perpendicular to the moving direction of the systems (Fig. 7).

With the beginning of the rains, the National Meteorological Administration through the Regional Meteorological Center "Transylvania North" issued the following meteorological warnings (http://www.meteoromania.ro/avertizari-nowcasting/): 


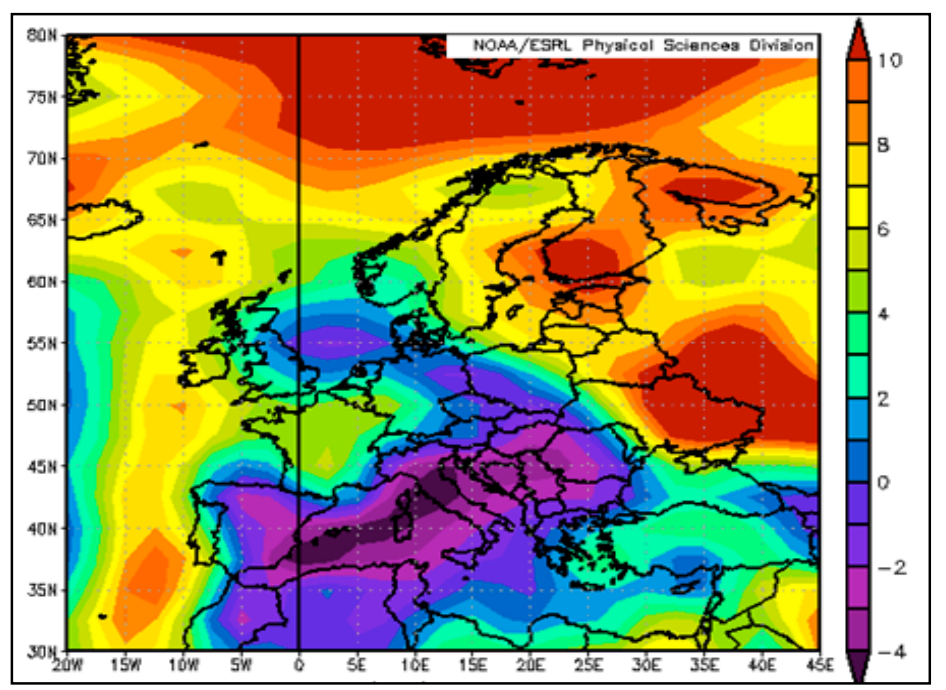

Fig. 6. Lifted index values on 01.08.2019, (https://www.esrl.noaa.gov/).

Nowcasting nr. 435, at 14:47 - Yellow warning of dangerous weather phenomena: warning phenomena: frequent lightnings, rain showers that locally will exceed $20 \ldots 25$ $\mathrm{mm}$, short-term intensification of the wind, small hail; areas targeted: Satu-Mare district: Certeze; interval of viability: 01/08/2019 14:50 - 01/08/2019 16:00.

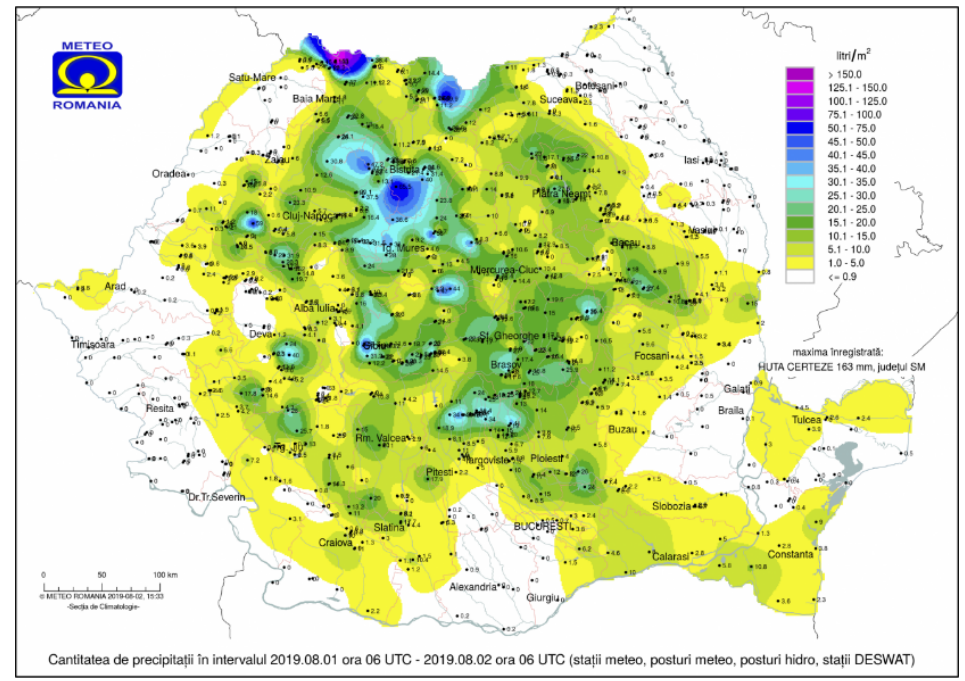

Fig. 7. Accumulated precipitation amounts on 01.08.2019 in Romania, (www.meteoromania.ro).

Nowcasting nr. 437, at 15:35 - Orange warning of dangerous weather phenomena: warning phenomena: torrential rains that will exceed $35 \ldots 40 \mathrm{~mm}$, hail of small and possibly medium size, short-term intensification of the wind, frequent 
lightnings; areas targeted: Satu-Mare district: Certeze; interval of viability: 01/08/2019 15:40 - 01/08/2019 16:30.

The total amount of water measured at Huta Certeza h.s. was $132.5 \mathrm{~mm}$ (Fig. 8).

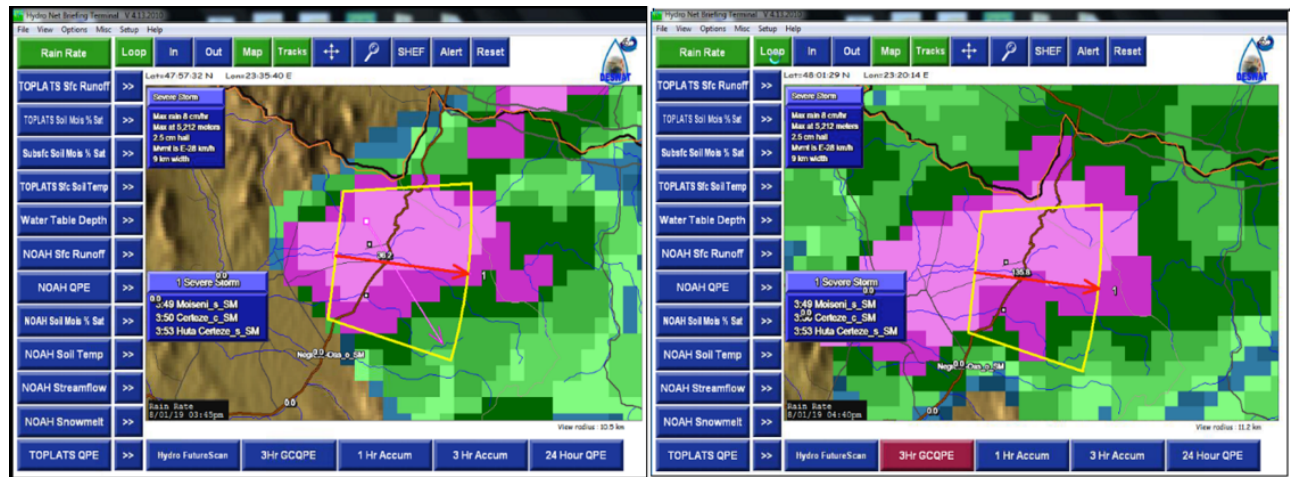

Fig. 8. The succession of cloud systems

(Hydro Net Briefing Terminal - Romanian National Water Administration)

The smaller quantities of precipitation measured at the neighboring meteorological stations also proves the local character of the pluvial event, namely: Negrești Oaș (south) $17.1 \mathrm{~mm}$ and Boinești (west) $19.4 \mathrm{~mm}$.

The pluvial event from 01.08.2019, produced in the related river basin of Huta Certeze h.s. on the Valea Rea river is of unprecedented magnitude, representing the maximum quantity measured at the meteorological and rain gauge stations in the Someș-Tisa basin. Based on the recorded data at the meteorological stations in the northwest part of Romania, between 1961 and 2019, the maximum amounts of measured precipitation in 24 hours were as follows (table 2):

Table 2. Maximum amounts of precipitation dropped between 1961-2019 (Archive Regional Meteorological Center "Transylvania North")

\begin{tabular}{|c|c|c|c|c|}
\hline \multirow{2}{*}{$\begin{array}{c}\text { Meteorological } \\
\text { station }\end{array}$} & \multicolumn{2}{|c|}{$\begin{array}{c}\text { 24 hours' maximum in summer } \\
\text { period }\end{array}$} & \multicolumn{2}{c|}{24 hours annual maximum } \\
\cline { 2 - 5 } & Data & Value [mm] & Data & Value [mm] \\
\hline Baia Mare & 27.08 .1966 & 71.8 & Mai. 1970 & 121.4 \\
\hline Satu Mare & 09.06 .1971 & 69.4 & Oct. 2003 & 71.0 \\
\hline Sighetu Marmației & 19.08 .1968 & 80.3 & Aug. 1968 & 80.3 \\
\hline Ocna Sugatag & 28.07 .2004 & 81.8 & Oct. 2003 & 82.2 \\
\hline Iezer & 29.07 .1966 & 80.8 & Iul. 1966 & 80.8 \\
\hline
\end{tabular}

According to Sandu et al. (2008), "The mean annual maximum quantities in 24 hours (1961-2000)", in the studied basin was between 50-60 mm. From the analysis of the distribution of the annual values of the maximum amount of precipitation in 24 hours, based on the data recorded at the meteorological stations in the Someș-Tisa basin, it is highlighted that the highest frequency is between 20 and $60 \mathrm{~mm}(89.7 \%)$, 
amount of precipitation below $20 \mathrm{~mm}$ have a weight of $1.7 \%$, and those over $60 \mathrm{~mm}$, $8.4 \%$. Amounts greater than $100 \mathrm{~mm}$ are rare, during the studied period, 1961-2011 was registered only one such value, in 1970 in Baia Mare, $121.4 \mathrm{~mm}$ (PPPDI, 2014).

The maximum level observed at the cross section of Valea Rea river at Huta Certeze h.s. was $225 \mathrm{~cm}$ from the " 0 hydrometric gauge", exceeding by $25 \mathrm{~cm}$ the alert stage. Defined river flooding stages are: warning stage (yellow) $-170 \mathrm{~cm}$, alert stage (orange) - 200, emergency stage (red) $-240 \mathrm{~cm}$. Starting from the base flow of $0.265 \mathrm{~m}^{3} / \mathrm{s}$, observed in the morning of the event, the maximum water discharge recorded was $46.6 \mathrm{~m}^{3} / \mathrm{s}$, produced at $5.30 \mathrm{pm}$, resulting a single peak-flood.

\subsection{Theory and Methodology}

For modeling the flash flood that occurred on the $1^{\text {st }}$ of august 2019, we used the hydrological model of MIKE HYDRO River by DHI that uses the Unit Hydrograph Method (UHM) from the Rainfall-Runoff Module, in order to obtain the runoff hydrograph recorded at the hydrometric station.

The model includes a number of simple unit hydrograph models to estimate the runoff from single storm events by the use of the well-known unit hydrograph technique. The models divide the storm rainfall in excess rainfall (or runoff) and water loss (or infiltration), (DHI, 2017).

The following parameters are used for all types of UHM models: Adjustment and baseflow, Hydrograph, Enlargement and loss model, Lag time.

Area adjustment factor. This adjustment factor (different from 1.0) may be applied if the catchment rainfall intensity is assumed to differ from the input rainfall data series by a proportional factor.

Baseflow. If different than zero, the value specified represents a constant baseflow that is added to the runoff.

The distribution of the runoff in time can be described using different methods. Three different options can be selected for the hydrograph type:

SCS triangular. This is a standard hydrograph in which the time to peak is assumed to be half the duration of the excess rainfall plus the lag time $t_{1}$.

SCS dimensionless. This type of hydrograph has been derived from a large number of natural unit hydrographs from catchments of varying size and location. The flow values are expressed in $Q / Q p$, where $Q p$ is the peak discharge, and the time in $\mathrm{T} / \mathrm{Tp}$, where $\mathrm{Tp}$ is the time from the start of the hydrograph rise to the peak.

User defined. This hydrograph should be specified in its dimensionless form, i.e. Q/Qp as a function of T/Tp, as for the SCS dimensionless hydrograph above (DHI, 2017).

In the unit hydrograph module, the excess rain is calculated assuming that the losses to infiltration can be described as a fixed initial and constant loss, a proportional loss (the rational method) or by the SCS curve number method (DHI, 2017). Four different options are available to represent the loss model, each of them requiring different inputs (Fig. 9).

Constant loss. In this case, the infiltration is described as an Initial Loss at the beginning of the storm followed by a Constant Loss term caused by infiltration. 
Proportional loss. If this model is selected, a Runoff coefficient should be specified as the ratio of runoff to the rainfall.

SCS method. The SCS Loss Model uses a Curve Number that characterizes the catchment in terms of soil type and land use characteristics. The model also requires an Initial AMC (antecedent moisture conditions) parameter (DHI, 2017).

The hypothesis of the SCS method is that the ratios of the two actuals to the two potential quantities are equal, that is (DHI, 2017).

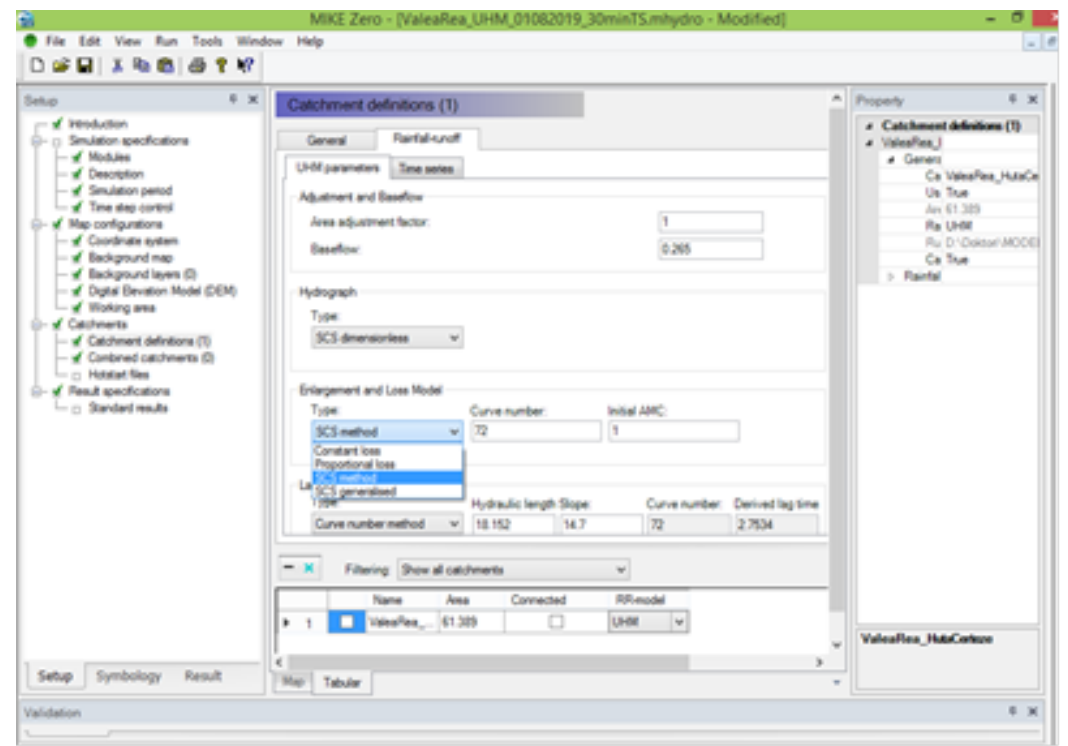

Fig. 9. Mike Hydro River - UHM model, set up options and inputs

$\frac{F_{a}}{S}=\frac{P_{e}}{P-I_{a}}$

Where, for the storm as a whole, the depth of excess precipitation or direct runoff $P_{e}$ is always less than or equal to the depth of precipitation $P$; likewise, after runoff begins, the additional depth of water retained in the watershed, $F_{a}$, is less than or equal to some potential maximum retention $S$. There is some amount of rainfall $I_{a}$ (initial loss before ponding) for which no runoff will occur, so the potential runoff is $P-I_{a}$ (Ivănescu et al, 2014).

From the continuity principle:

$P=P_{e}+I_{a}+F_{a}$

The method involves the use of a curve number $(\mathrm{CN})$, hence its name (SCS-CN), and is based on an equation that assumes the relationship between rainfall and runoff, according to USDA (1986).

$Q=\frac{\left(\mathrm{P}-I_{a}\right)^{2}}{\left(P-I_{a}\right)+S}$

Where: Q - layer of runoff $(\mathrm{mm}) ; \mathrm{P}$ - precipitation $(\mathrm{mm}) ; \mathrm{I}_{\mathrm{a}}$ - initial loss $(\mathrm{mm}) ; \mathrm{S}$ potential maximum retention. 
The initial loss $I_{a}$ (abstractions) represent all the water losses that occur before the runoff begins (evaporation, water retained in the small depressions, infiltration). Following studies affected on small basins, it was discovered that the initial losses can be calculated according to the formula (USDA, 1986):

$\mathrm{I}_{\mathrm{a}}=0.2 \mathrm{~S}$

Substituting the computation relation, the equation can be followed further:

$\mathrm{Q}=\frac{(\mathrm{P}-0.2 \mathrm{~S})^{2}}{(\mathrm{P}+0.8 \mathrm{~S})}$

Where: Q - layer of runoff $(\mathrm{mm})$; P - precipitation $(\mathrm{mm}) ; \mathrm{S}$ - potential maximum retention.

The calculation relation of the maximum retention potential is based on the $\mathrm{CN}$, this being a parameter dependent on the hydrological group of soils and the land use at the level of the river basin. From this point of view the soils were classified into 4 hydrological groups (A, B, C and D), depending on the rate of water infiltration (USDA, 1986).

$S=\frac{25400}{C N}-254$, applicable for normal moister conditions (AMC II)

For dry conditions (AMC I) or humid (AMC III) the equivalent of CN can be calculated by the relations:

$C N_{I}=\frac{\left(-75 \cdot C N_{I I}\right)}{\left(-175+C N_{I I}\right)}$

$C N_{I I I}=\frac{\left(175 \cdot C N_{I I}\right)}{\left(75+C N_{I I}\right)}$

SCS generalised. The SCS generalised loss model does not make use of the concept of an antecedent moisture content (AMC) but applies a storage Initial abstraction depth. Like in the SCS method, the $C N$ should be specified for the SCS generalised.

The Lag time type for the UHM model can be specified in two different ways:

User specified. In this case, the lag time is specified directly in hours.

Curve number method. In this case, the lag time is calculated by the standard SCS formula and will appear in the Derived Lag Time box. When this method is selected, three parameters need to be specified: Hydraulic length, the Slope of the catchment and the Curve number (DHI, 2017).

For the study area, these values were calculated using ArcMap and a DEM with a resolution of $3 \mathrm{~m}$, which is represented as follows: Hydraulic length: $18.155 \mathrm{~m}$ and Slope: $14.7 \%$.

A unit hydrograph can be characterized by the duration of the unit rainfall $\left(\mathrm{t}_{\mathrm{r}}\right)$ resulting in the hydrograph and the lag time $\left(\mathrm{t}_{1}\right)$ defined as the time difference between the center of the unit rainfall event and the runoff peak. From these two characteristics, the time to peak $\left(T_{p}\right)$, i.e. the time from the start of the storm event until the occurrence of peak runoff can be calculated as (DHI, 2017):

$\mathrm{T}_{\mathrm{p}}=\mathrm{t}_{\mathrm{r}} / 2+\mathrm{t}_{\mathrm{l}}$ 


\section{RESULTS AND DISCUSSIONS}

The simulation of the flash flood was performed with MIKE HYDRO River UHM, using as input data the precipitation measured at Huta Certeze h.s. For the calculation of infiltration losses all four methods, presented in the previous chapter were used. Several trials were performed, error simulations with different values of the calibration parameters, till we established a value for the parameters, that led to a discharge hydrograph similar to the measured hydrograph, by phase and amplitude. Description of simulations

Simulation period: simulation start: 2019-07-31 06:00:00 - simulation end: 2019-08-03 18:00:00. The automatic calculation of the catchment basin area was

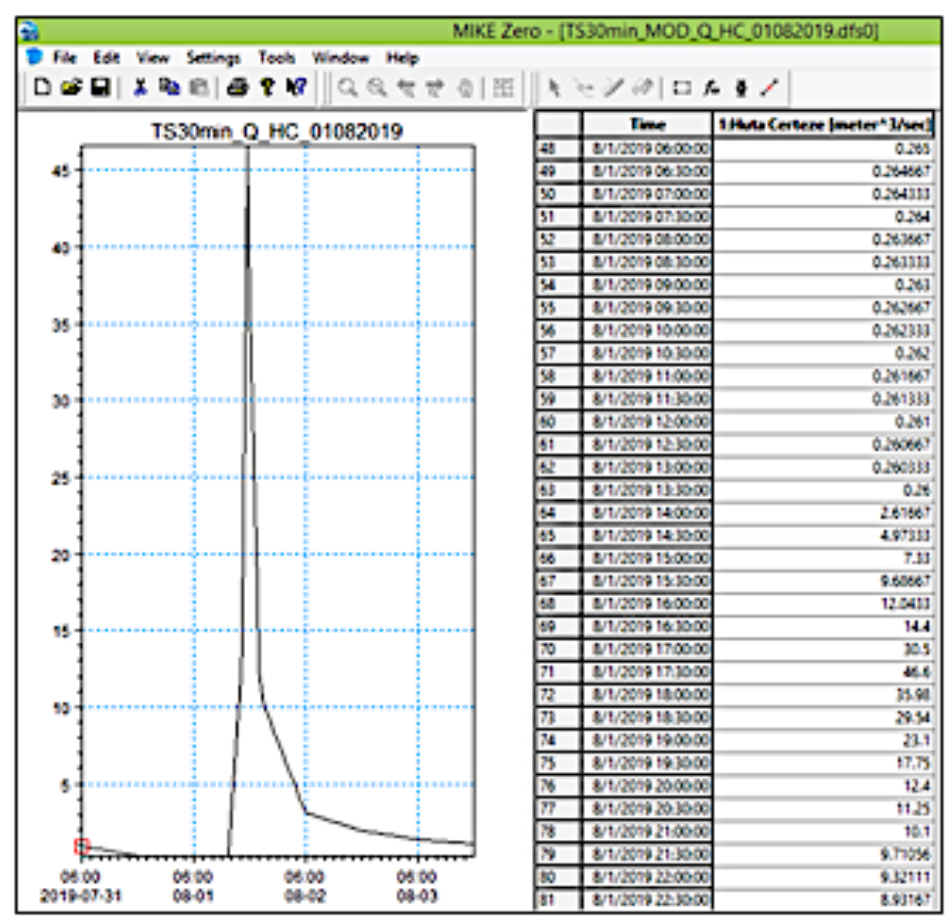

Fig. 9. Discharge time series performed using a polygon type shp file, extracted with ArcMap software from a Digital Elevation Model, resulting in $61.3 \mathrm{~km}^{2}$.

For the baseflow, the value of 0.265 $\mathrm{m}^{3} / \mathrm{s}$ was introduced. The time series were determined based on the accuracy of the available data. Before creating the discharge time series, it was necessary to reconstruct the flood. We

corrected the increasing branch of the hydrograph resulting from the observed levels, with the once transmitted by the automatic station, in order to determine as accurately as possible, the start time of the flood. The flows were interpolated by running the CAVIS program (INHGA), with the chosen time step of 30 minutes, after which they were reproduced in MIKE (Fig. 9). In the case of precipitation, the same time series were used (Fig. 10).

The challenge is to obtain the appropriate parameters for describing the initial conditions (Table 3).

\section{Constant Loss}

Several simulations were performed, gradually decreasing the constant infiltration through the rain. The conclusion is that the value of $48 \mathrm{~mm}$ for Initial Loss and $30 \mathrm{~mm} / \mathrm{h}$ 
for Constant Loss led to a peak discharge of $48.5 \mathrm{~m}^{3} / \mathrm{s}$, which represent an amplitude error of $+4.1 \%$ and +30 min delay, compared to the maximum recorded discharge of $46.6 \mathrm{~m}^{3} / \mathrm{s}$. The analysis of the results showed that the maximum peak simulated is an inverse ratio of the Constant Loss parameter. The excess rainfall that produces the surface runoff is diminished by the constant infiltration through the storm. The increase of the Constant Loss parameter doesn't influence the moment of occurrence of the hydrograph peak. The Lag time was set by the User specified method, which is $2.53 \mathrm{~h}$.

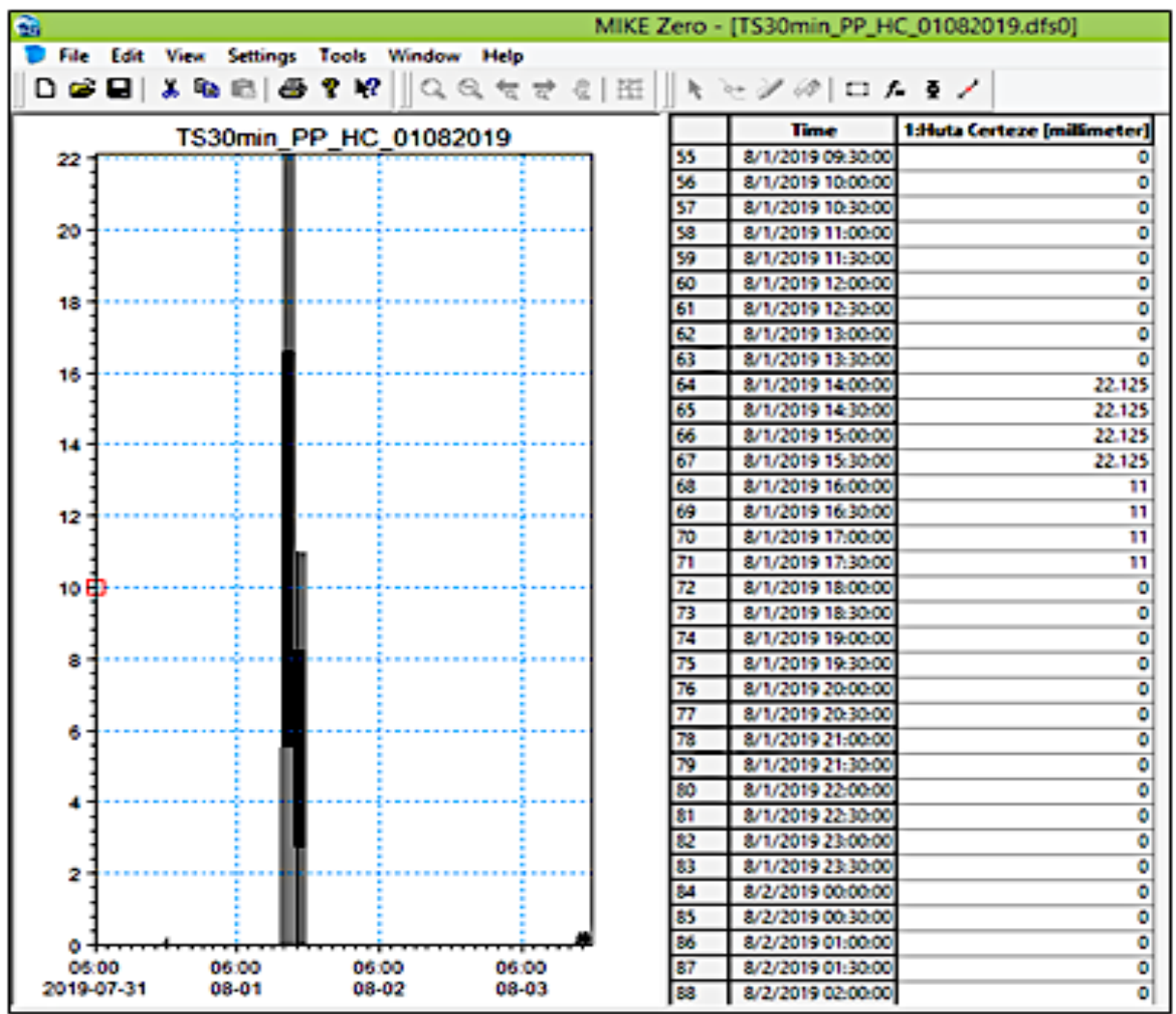

Fig. 10. Precipitation time series

\section{Proportional Loss}

Several simulations were performed, gradually decreasing the value for the parameter Runoff coefficient, starting with the value 0.15 , till we established a value for the parameter which led to a discharge hydrograph similar to the measured hydrograph, by phase and amplitude. We reached the conclusion that the value of 0.1 for the parameter Runoff coefficient led to a peak discharge of $46.1 \mathrm{~m}^{3} / \mathrm{s}$, which represent an amplitude error of $-1 \%$ and +30 min. delay, compared to the maximum recorded discharge. The analysis of the results shows that the maximum peak simulated is an inverse ratio of the Runoff coefficient parameter, that diminishes the excess rainfall and therefor the surface runoff. The increase or decrease of the Runoff coefficient parameter doesn't influence the moment of occurrence of the hydrograph peak. The Lag time was set by the User specified method, which is $2.53 \mathrm{~h}$. 
The discharge hydrograph simulated with the Proportional Loss method gives the most credible the moment of the breakout and propagation of the flash flood compared to the characteristics of the observed hydrograph, being authenticated by the auto-calibration results used by MIKE: $\mathrm{R}^{2}=0.60$, WBL $=7.16 \%$ (Fig. 11).
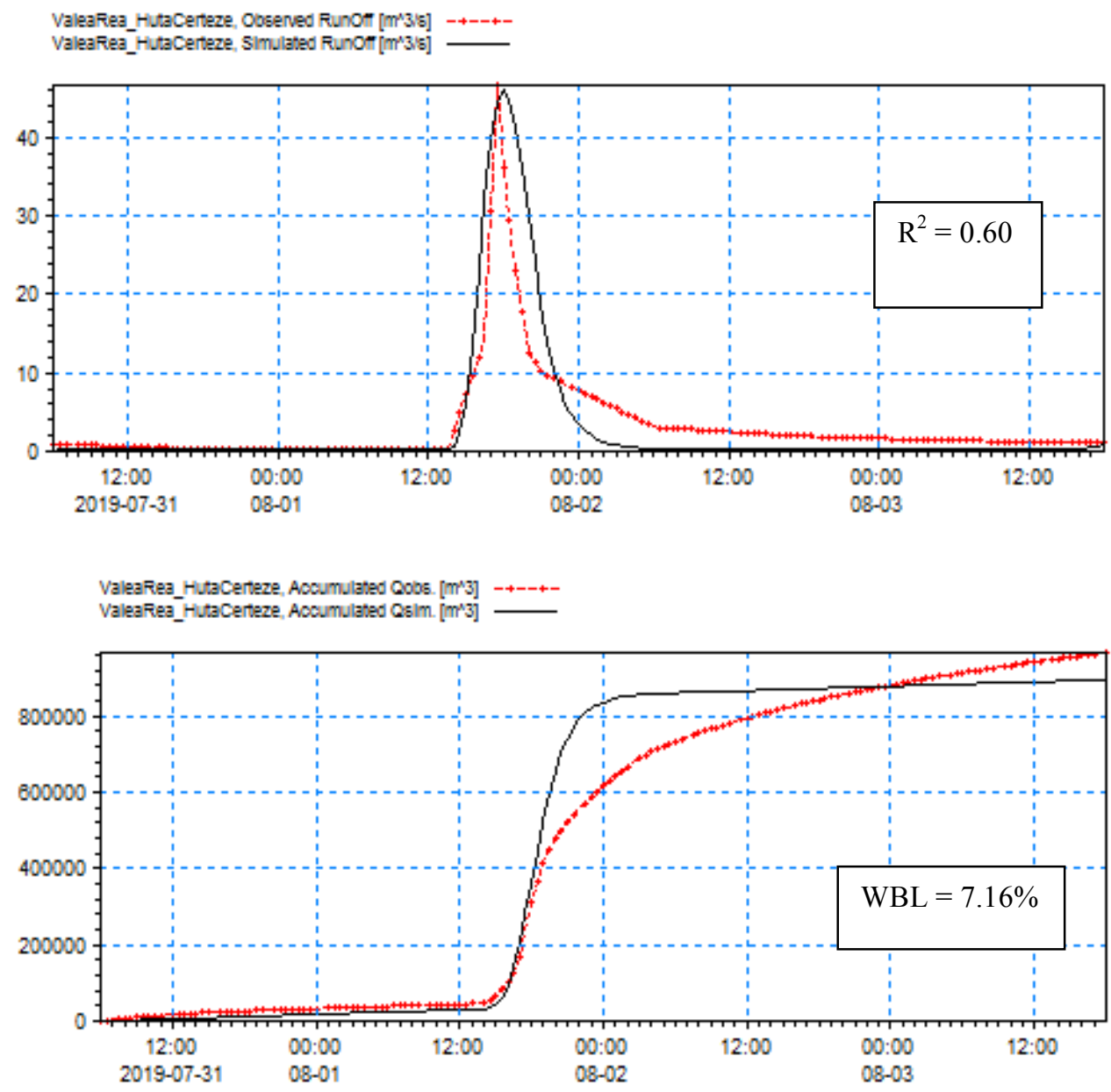

Fig. 11. UHM auto-calibration, Proportional loss method.

\section{SCS method}

As presented above, in the study area the clay soils predominate, with a reduced water infiltration capacity, falling within the $\mathrm{B}$ and $\mathrm{C}$ hydrological soil group. The CN parameter was calculated by the weighted method established in TR-55 (Technical Release - 55) by the United States Department of Agriculture. Thus, the initial calculated CN parameter was 72, for normal moister conditions.

For determination of the AMC index, the total amount of precipitation recorded in 5 days before the event at Huta Certeze h.s. were taken into consideration, the respective value being $36.7 \mathrm{~mm}$. According to the limits established by McCuen in 
1982 for the vegetation period, this amount would fit into the AMC II group (35.6 $53.4 \mathrm{~mm}$ ). Considering that the value of $36.7 \mathrm{~mm}$ is at the limit between the groups of AMC I - AMC II, and analyzing the amount of precipitation over a longer period we decided that in the modelling processes should be applied the AMC I. Following the calibration steps of the model, the obtained $\mathrm{CN}$ value was 63 .

The simulation resulted a peak discharge of $44.1 \mathrm{~m}^{3} / \mathrm{s}$, which represent an amplitude error of $-5.4 \%$ and +2 hours' delay, compared to the maximum recorded discharge. The Lag time was set by the User specified method, which is $2.53 \mathrm{~h}$ (Fig. 12).

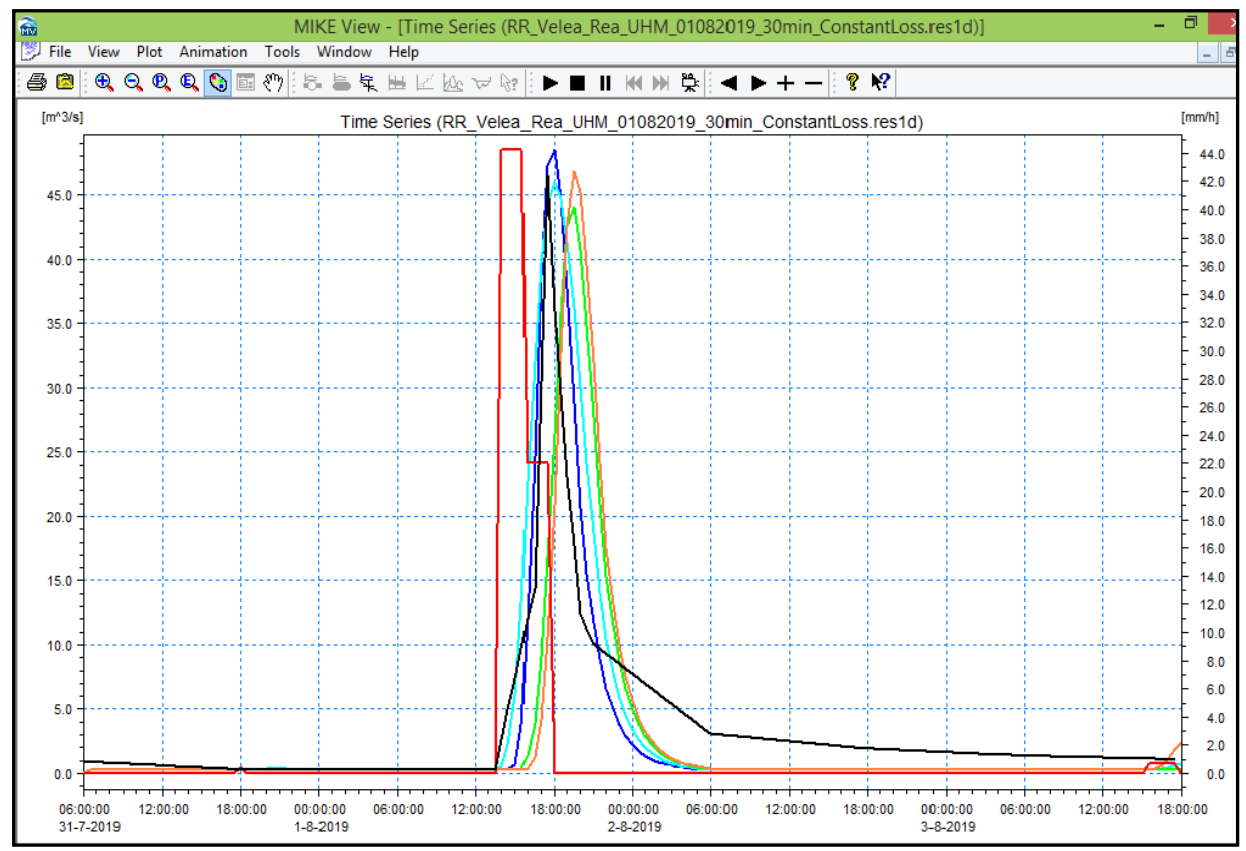

Fig. 12. Discharge hydrograph (_ recorded, _Constant Loss, Proportional Loss, _ SCS method,__ SCS generalised, Observed precipitation)

\section{SCS generalized}

Several simulations were performed using different values for the Initial abstraction depth parameter, till we established a value for the parameter which led to a simulated discharge hydrograph similar to the observed hydrograph. We reached the conclusion that the value of $87 \mathrm{~mm}$ for the Initial abstraction depth led to a peak discharge of $46.9 \mathrm{~m}^{3} / \mathrm{s}$, which represent an amplitude error of $+0.6 \%$ and +2 hours' delay, compared to the maximum recorded discharge.

The Lag time and Area adjustment factor parameters are identical for all 4 methods, being 2.53 , respectively 1 .

The auto-calibration is done to optimize two objective functions: (a) minimizing the water balance error (\%WBL) to achieve agreement between the average simulated and observed runoff, and (b) minimizing the overall Root Mean Square Error (RMSE) for the entire flow spectrum to achieve overall agreement of the shape of the hydrograph. 
Table 3. Simulation results

\begin{tabular}{|c|c|c|c|c|c|}
\hline \multirow{2}{*}{$\begin{array}{c}\text { Infiltration } \\
\text { Losses Model } \\
\text { Type } \\
\end{array}$} & \multirow[t]{2}{*}{ Parameters } & \multirow{2}{*}{$\begin{array}{l}\text { Accumulated } \\
\text { Volume }\left[\mathrm{m}^{3}\right]\end{array}$} & \multirow{2}{*}{$\begin{array}{c}\text { Maximum } \\
\text { simulated } \\
\text { discharge }\left[\mathrm{m}^{3} / \mathrm{s}\right]\end{array}$} & \multicolumn{2}{|c|}{$\begin{array}{c}\text { Errors compared to the } \\
\text { maximum discharge recorded }\end{array}$} \\
\hline & & & & amplitude & phase \\
\hline Constant Loss & $\begin{array}{l}\text { Initial loss: } 48 \mathrm{~mm} \\
\text { Constant loss: } 30 \mathrm{~mm} / \mathrm{h} \\
\text { Lag time: } 2.53 \\
\text { Area adjustment factor: } 1 \\
\end{array}$ & 736755.40 & 48.5 & $+4.1 \%$ & $+30 \mathrm{~min}$ \\
\hline $\begin{array}{c}\text { Proportional } \\
\text { Loss }\end{array}$ & $\begin{array}{l}\text { Runoff coefficient: } 0.1 \\
\text { Lag time: } 2.53 \\
\text { Area adjustment factor: } 1\end{array}$ & 896280.71 & 46.1 & $-1 \%$ & $+30 \min$ \\
\hline SCS method & $\begin{array}{l}\mathrm{CN}=63 \\
\text { Initial AMC }=1 \\
\text { Lag time: } 2.53 \\
\text { Area adjustment factor: } 1\end{array}$ & 728506.90 & 44.1 & $-5.4 \%$ & $+2 \mathrm{~h}$ \\
\hline $\begin{array}{c}S C S \\
\text { generalised }\end{array}$ & $\begin{array}{l}\mathrm{CN}=63 \\
\text { Initial abstraction depth: } 87 \\
\text { Lag time: } 2.53 \\
\text { Area adjustment factor: } 1\end{array}$ & 745127.34 & 46.9 & $+0.6 \%$ & $+2 \mathrm{~h}$ \\
\hline
\end{tabular}

The coefficient of determination or the Nash-Sutcliffe coefficient, which is commonly adopted for evaluating the goodness-of-fit of the simulated hydrograph is a transformed and normalized measure of the overall RMSE (normalized with respect to the variance of the observed hydrograph), (Madsen, 2000). Table 4 shows the results of auto-calibration yielded \% WBL and $\mathrm{R}^{2}$ values.

Table 4. Results of auto-calibration

\begin{tabular}{|c|c|c|}
\hline Infiltration Losses Model Type & $\mathrm{R}^{2}$ & $\% \mathrm{WBL}$ \\
\hline Constant Loss & 0.74 & 23.68 \\
\hline Proportional Loss & 0.60 & 7.16 \\
\hline SCS method & 0.19 & 24.54 \\
\hline SCS generalised & -0.09 & 22.82 \\
\hline
\end{tabular}

\section{CONCLUSIONS}

The obtained results can be influenced by many factors, especially if the data source is incomplete or inaccurate, by the methods used in data processing, their interpretation, respectively the accuracy of the calibration steps of the simulation models. MIKE HYDRO River - UHM being a model with concentrated parameters it's difficult to obtain results where all correspond with the parameters of the observed hydrograph. The increasing branch of the hydrograph can be modeled with much higher accuracy than the decreasing one. Flash floods are one of the most unpredictable and difficult to anticipate natural phenomena, such as space, time and amplitude. The extraordinary amount of precipitation, in total of $132.5 \mathrm{~mm}$, with torrential character, produced on 01.08.2019 in a very short time of only 4 hours, in the river basin of Huta Certese h.s., generated a rapid increase of the flows, reaching a peak discharge of 46.6 $\mathrm{m}^{3} / \mathrm{s}$. Given that flash floods can occur under various climatic conditions, it is necessary to simulate them under different scenarios. Simulating this hydrometeorological event with the modification of the antecedent moister conditions, 
from AMC I to AMC II, and implicitly the $\mathrm{CN}$ parameter at 72 , the maximum discharge would be over $160 \mathrm{~m}^{3} / \mathrm{s}$, far exceeding the maximum measured historical flow, increasing the number of people exposed to the potential risk on inundations.

The good results obtained with all four methods confirm that MIKE HYDRO River - UHM can be used for forecasting water flows to rivers or lakes, for estimating water resources, as well as for river basin management.

\section{ACKNOWLEDGMENT}

This work was made possible by the permanent support from DHI Romania, in terms of professional trainings and provided educational license for MIKE HYDRO River. We owe thanks to the colleagues from Regional Meteorological Center "Transylvania North" and "Someș-Tisa" Water Basin Administration for providing the primary data needed for simulation.

\section{REFERENCES}

1. DHI (2017), MIKE HYDRO River. User guide. Danish Hydraulic Institute.

2. DHI (2017), MIKE 11: A Modeling System for Rivers and Channels. Reference Manual. Danish Hydraulic Institute, Denmark.

3. Ivănescu V., Drobot R. (2016), Deriving rain threshold for early warning based on a coupled hydrological-hydraulic model. Mathematical Modelling in Civil Engineering, Vol. 12-No. 4: 10-21-2016 DOI: https://doi.org/10.1515/mmce-2016-0014

4. Haidu I. (1993), Evaluarea potențialului hidroenergetic natural al rîurilor mici din Carpații Maramureșului și Bucovinei (in Romanian).

5. Sandu I., Pescaru V.I., Poiană I., Administrația Națională de Meteorologie (2008), Clima României. București, Editura Academiei Române (in Romanian).

6. Ivănescu V., Mocanu P., Sandu M. A. (2014), Application of a hydrodinamic Mike 11 model for Argesel River. DOI: 10.5593/SGEM2014/B31/S12.009

7. Madson H. (2000), Automatic calibration of a conceptual rainfall-runoff model using multiple objectives. Journal of Hydrology 235: 276-288 DOI: 10.1016/S0022-1694(00)00279-1.

8. Strapazan C., Haidu I., Kocsis I. (2019), Assessing land use/land cover change and its impact on surface runoff in the southern part of the Tibleș and Rodnei Mountains. 2019 "Air and Water - Components of the Environment" Conference Proceedings, ClujNapoca, Romania, p. 225-236, DOI: 10.24193/AWC2019_23.

9. Talchabhadeli R., Shakya N. M. (2015), Rainfall runoff modelling for flood forecasting (A case study on west Rapti watershed). Journal of Flood Engineering, Vol. 6. DOI: https://dx.doi.org/10.4236/gep.2014.25001

10. Bălan I., Crenganiș L., Corduneanu F. (2015), Flood analysis using Mike 11 by DHI and ArcGIS. Case study - The flood in the upper catchment of river Geru, Galați Country, Romania. URL: http://geomat.ro/registration.php

11. ***PPPDEI (2014), Planul pentru prevenirea, protecția și diminuarea efectelor inundațiilor $\hat{i n}$ bazinul hidrografic Someș Tisa, S.C. AQUAPROIECT S.A (in Romanian). URL: $\mathrm{http} / / /$ www.rowater.ro/dasomes/Documente/Proiect\%20PPPDEI/PPDEI_varianta_initiala.pdf 